\title{
Das Bartleby-Syndrom
}

Enrico Danieli

Korrespondenz:

Dr. med. Enrico Danieli

Via ai Colli 22

CH-6648 Minusio

e.b.danieli@bluewin.ch
Ergeht es Ihnen manchmal auch so, dass Sie in Betrachtung sogenannter Kunstwerke ins Sinnieren verfallen, Sie sich vorstellen (oder es sich gar wünschen), dass die gezeigten Objekte nicht da wären, dass Ihnen (ganz ehrlich gesagt) die Leere, ein weisses leeres Blatt, ein leeres Podestament lieber wären: bedeutsamer als alles andere um Sie herum?

Ich nehme an, dass Sie die Entität einer solchen «Krankheit» nicht kennen, Sie nicht im Detail wissen, wovon die Rede ist: von einem Krankheitsbild, das mehr Intellektuelle befällt, Menschen in geordneten Verhältnissen mit Integration in Familie, Beruf, Staat; Menschen, von denen im Vorhinein nicht angenommen werden kann, dass sie zu den Verletz-, Verwundund Verschwindbaren dieser Welt gehören. Und doch sind es diese wie Uhren Funktionierenden, deren einziger Satz (einmal schuldhaft ausgesprochen) ganze Leben, Beruf, Familie, Ehrgeiz, Sinngebung, Liebe zerstört: «Ich würde vorziehen, es nicht zu tun.» Oder: «Ich weiss es nicht.» Zweifler, Hinterfrager, Neinsager, Zweifelsüchtige leiden am Bartleby-Syndrom. Haben Sie, Hand aufs Herz, diesen einen Satz in irgendeinem Zusammenhang nicht auch schon selber gedacht? Hüten Sie sich vor ihm, fliehen sie ihn, bevor es zu spät ist, verschliessen Sie Augen und Ohren: Denn was kommt, ist Negation pur (in $\mathrm{x}$-fachen Varianten). Nennen wir «es» beim Namen: schwarze Phasen, schwarze Verfassung, schwarze Tage, schwarze Zeiten - die Schattenzonen (des Seins). Solange solche Phasen gelingen, sprechen wir von Melancholie, scheitern auch sie, von Depression.

Bartlebys sind Menschen, die eine tiefe Abneigung gegen die Welt hegen. Sie verdanken den Namen ihrer Krankheit dem Büroangestellten aus einer Erzählung Herman Melvilles. Es sind Leute, die man nicht lesen, nicht schreiben, nicht sprechen, sondern «still-stehen» sieht.

Bartleby heisst Mensch gewordene Negation. Bartleby kann sich in verschiedenen Formen äussern, die Grundierung heisst Faszination für das Nichts. Die Folge ist, dass manches nicht (oder nie) getan werden wird, was getan werden sollte. Es ist eine intellektuelle Entsagung: kein Schreiben, kein Musizieren, kein Malen - nichts geht mehr; es bleiben Leere, Negation, das Nichts zurück; und vom Menschen eine Hülle. Wer fällt Ihnen als Beispiel ein? Es sind Legionen von bleiben wir im Bild der Sprache - Schriftstellern, die auch/oder die Bartlebys sind, allen voran Robert Walser, er, der sagte, darüber zu schreiben, dass man nicht schreibe, sei auch eine Art von Schreiben ... Konsequenterweise werden die meisten Bücher gar nicht ge- schrieben, da man nicht bis zum ersten Buch (oder Werk) kommt; diese (nicht) geschriebenen Bücher gehörten demgemäss, als Intention sozusagen und als Opfer der Krankheit, auch zu den Bestandteilen der (ungeschriebenen) Weltliteratur.

Bobi Bazlen aus Triest, der kein einziges Buch veröffentlicht hat und doch als grosser Schriftsteller (Kritiker) gilt, Hofmannsthal im Lord-Chandos-Brief, Primo Levi (Atempause): die Liste ist ohne Ende. Es ist das Verstummen, das die Sich-Verneinenden eint. Es geht dabei (wie meistens in der Kunst) um radikale Verweigerung. Wie oder was suchen (in der Kunstausübung), wenn man nicht einmal weiss, was man sucht? Nicht zufällig denken Sie an Kafka, an seinen «Hungerkünstler», und, so könnte man themenbezogen folgern, dass dieser nicht «schreiben» kann, weil ihm das Richtige nicht eingefallen ist. Diese Verneiner sind definitionsgemäss Neinsager, d.h. Rebellen. Sie leben in einer Schattenzone, dort, wo die radikalste aller Negationen beheimatet ist: wo Kälte wohnt, Zerstörung, Tod. Denken wir diesen Ansatz weiter, so ist, naturgemäss, die letzte aller Negationen das Schweigen, das Verstummen, die Grabesstille. Borges, Pessoa, Musil, Broch, Celan, Rimbaud, Keats: Um nur einige der berühmteren Bartlebyaner zu nennen, eine Reihe, die sich immer weiter fortsetzen lässt.

Erdrückend sind sie schon, die vielen schwarzen Sonnen über uns. Und wieder Robert Walser, er, der vielleicht als Erster ein reiner Bartlebyaner war, denn er wollte nur eins: verschwinden und in der Anonymität untertauchen (was ihm wie keinem anderen gelungen ist). Das Scheitern ist, Ende und Anfang, die unmittelbare Ursache des Syndroms, die Folge ist der Verzicht auf jede Art von Kunstausübung. Die Verwirklichung des Nichts-Tuns ist Ausdruck der inneren Vernichtung. Die Verlockungen des Scheiterns sind dabei so gross, dass viele dieses dem Nichtschweigen vorziehen, auch wenn sie daran leiden: Stillstand, Sonnenfinsternis, Stille. Am Schluss nur noch ein Stammeln, Stottern, Verstummen. Einem kreativen Menschen stehen zwei Möglichkeiten zur Verfügung: Er ist kreativ, oder aber er verzichtet auf diese. Das ist höhere Kraft der Negation: Sie bietet mehr an Möglichkeiten! Prinzipiell gilt, dass das Nichts nicht automatisch auch weniger ist als das Etwas; oder, um ein Bild zu bemühen: Bartlebyaner leben im steten Gefühl, die Leinwand, den Rahmen, zu sprengen - sie bemühen sich, das Unendliche einzurahmen. Als Einstieg: Enrique Vila-Mates: Bartleby \& Co. (mit einem Handbuch für Bartlebyaner). 